\title{
Pemodelan Kebisingan akibat Aktifitas Pesawat dan Optimalisasi Kebisingan di Bandara Juanda dengan Menggunakan Model Les Frair
}

\author{
Brigita Sance, Mardlijah, dan Nur Asiyah \\ Departemen Matematika, Fakultas Matematka dan Ilmu Pengetahuan Alam, Institut Teknologi Sepuluh \\ Nopember (ITS) \\ e-mail:mardlijah@matematika.its.ac.id
}

\begin{abstract}
Abstrak-Kebisingan pada bandar udara akibat aktifitas pesawat terbang banyak ditemui di Indonesia. Banyaknya jumlah permintaan penerbangan dan angkutan barang mengakibatkan berbagai maskapai menambah jumlah penerbangan. Kesibukan penerbangan yang terjadi pada bandara mengakibatkan tingkat kebisingan semakin bertambah. Batasan penerbangan dilakukan untuk meminimalkan kebisingan. Pada studi kasus dalam penelitian ini yaitu Bandar Udara Juanda, jam operasional penerbangan yaitu pada jam 05.00 sampai dengan jam 22.00. Fungsi $W(L d n)$ diminimumkan pada titik kritis dengan melakukan pendekatan Taylorp. Tingkat kebisingan yang minimum dibentuk kedalam fungsi Ldn atau batas tingkat kebisingan pada siang dan malam. Penjadwalan penerbangan dimodelkan berdasarkan tingkat kebisingan minimum dan fungsi batas. Penurunan tingkat kebisingan setelah dioptimalkan diketahui dengan menghitung perbandingan indeks dampak kebisingan atau NII sebelum dan sesudah dioptimalkan. Indeks dampak kebisingan mengalami penurunan hingga $\mathbf{4 2 . 4 1 5 6 9 0 9 6 \%}$ tepatnya pada lokasi pengukuran 2, pada hari ke 2.
\end{abstract}

Kata Kunci-Bandara, Kebisingan, Model Matematika.

\section{PENDAHULUAN}

I NDONESIA memiliki 296 bandara, baik bandara domestik maupun internasional yang masing-masing dikelola oleh berbagai pihak [1]. Bandar Udara Juanda Surabaya merupakan bandara kedua tersibuk di Indonesia setelah Bandara Soekarno Hatta. Dalam lima tahun terakhir di Bandara Juanda, jumlah penerbangan mengalami kenaikan rata-rata $6,3 \%$ per tahun dan jumlah penumpang mengalami kenaikan rata-rata 7,7\% per tahun. Pada tahun 2016 terdapat 33.997 jumlah pergerakan pesawat, jumlah tersebut naik dari 28.866 pergerakan pada 2015 atau naik sebesar 17,78\% [2]. Banyaknya pesawat yang landing dan take off di Bandara Juanda mengakibatkan semakin tinggi tingkat kebisingan. Kebisingan pada bandara disebabkan oleh pengoperasian landing, take-off, dan dapat juga disebabkan oleh himpunan kebisingan lain yang tidak terpisahkan.

Gangguan psikologis akibat kebisingan tergantung pada intensitas, frekuensi, periode, saat dan lama kejadian, kompleksitas kegaduhan dan tidak teraturnya suara kebisingan [3]. Peningkatan jumlah penerbangan pada Bandara Juanda berpotensi meningkatkan tingkat kebisingan. Jenis Pembobotan A adalah pengukuran kebisingan yang digunakan dalam peraturan Menteri Perhubungan. A-weighted sound level atau tingkat kebisingan terbobot A selanjutnya disebut $\mathrm{dB}(\mathrm{A})$ adalah tingkat kebisingan maksimum yang dibaca dalam skala A [4]. Penelitian ini membahas mengenai model kebisingan pada daerah sekitar Bandara Juanda dan bagaimana meminimalkan kebisingan tersebut dengan mengoptimalkan jumlah pesawat terhadap lintasan landing maupun take off dan menjadwalkan pesawat berdasarkan lintasan kedatangan dan keberangkatan pesawat. Fungsi objektif dari model matematika tersebut akan diminimumkan pada total populasi gangguan yang mengakibatkan kebisingan. Solusi pada penelitian ini akan direpresentasikan berdasarkan hasil perhitungan gradien dan linier programming dan akan dilakukan simulasi pada MATLAB.

\section{URAIAN PENELITIAN}

Kebisingan adalah bunyi yang tidak dikehendaki karena tidak sesuai dengan ruang dan waktu sehingga dapat menimbulkan gangguan terhadap kenyamanan dan kesehatan manusia [5]-[6]. Baku tingkat kebisingan adalah batas maksimal tingkat kebisingan yang diperbolehkan dibuang ke lingkungan dari usaha atau kegiatan sehingga tidak menimbulkan gangguan kesehatan manusia dan kenyamanan lingkungan [7]. baku mutu kebisingan pada area pemukiman, sekolah dan rumah sakit adalah $55 \mathrm{db}(\mathrm{A})$, baku mutu pada fasilitas umum adalah $60 \mathrm{db}(\mathrm{A})$, baku mutu pada perdagangan dan perkantoran adalah $65 \mathrm{db}(\mathrm{A})$, baku mutu pada area perdagangan, industri dan rekreasi adalah $70 \mathrm{db}(\mathrm{A})$ [8].

Alat yang umum digunakan untuk mengukur bunyi adalah sound level meter. Sound level meter mengukur keseluruhan frekuensi suara atau bunyi yang diterima [6], [9]. Noise Exposure Level adalah tingkat kebisingan yang diijinkan dipaparkan ke lingkungan. Kebisingan yang terukur pada daerah tertentu dilambangkan dengan $L$. Kebisingan tingkat $L$ dapat diubah agar merepresentasikan kebisingan yang terjadi selama siang dan malam dengan Lsm. Nilai Lsm dirumuskan sebagai berikut :

$$
\operatorname{Lsm}=10 \log (1 / 24) \sum_{i=1}^{n} 10^{0,1 L_{i}}
$$

dengan :

$L_{i}$ tingkat kebisingan hasil pengukuran pada waktu $i$

Pola kebisingan yang terjadi terus-menerus disebut dengan tingkat kebisingan tidak tunggal atau noise exposure. Persamaan yang menggambarkan hubungan jumlah 
penerbangan dengan tingkat kebisingan dirumuskan dalam Noise Exposure (NE). NE dirumuskan sebagai berikut :

$N E=10 \log \left[(D+E+c N) 10^{E L / 10}\right]-p$ dengan:

$D, E, N$ jumlah penerbangan masing-masing pada pagi, siang dan malam

c faktor bobot $(\mathrm{NEF}=16.7$ dan $\mathrm{Ldn}=10)$

$E L$ paparan kebisingan yang terjadi (EPNL untuk $N E F$ atau $N E L$ untuk $L d n$ )

p 88,0 untuk $N E F$ dan 49,4 untuk $L d n$

Noise exposure dapat digunakan untuk menghitung nilai $L d n$ maupun NEF. $L d n$ adalah pengukuran kebisingan berdasarkan periode penerbangan. Terdapat beberapa penelitian yang sudah dilakukan sebelum penelitian ini. Penelitian yang dilakukan oleh Les Frair pada tahun 1983 meyatakan bahwa kebisingan pada bandara disebabkan oleh kumpulan kebisingan yang kemudian dihitung dengan NEF (Noise Exposure Forecast) [6]. Pada tahun 2008, Mohammad Chaeran mengukur dan mengevaluasi kebisingan akibat aktifitas pesawat di dalam Bandara dengan Ldn dan mengkaji dampak kebisingan terhadap responden [3]. Pada penelitian oleh Fahmi tahun 2012 kebisingan dipetakan berdasarkan nilai Leq dan WECPNL [10].

\section{ANALISA DAN PEMBAHASAN}

Berdasarkan hasil pengukuran kebisingan di tiga titik yang telah ditentukan, didapatkan fluktuasi tingkat kebisingan sebagai berikut (Tabel 1, 2 dan 3):

Tabel 1.

Fluktuasi Tingkat Kebisingan Hari Ke 1

\begin{tabular}{rrrrrr}
\hline \multirow{2}{*}{ No } & Periode & \multicolumn{2}{c}{ Tingkat Kebisingan $(\mathrm{dB})$} & \multirow{2}{*}{$\begin{array}{c}\text { Jumlah } \\
\text { Pesawat }\end{array}$} \\
\cline { 3 - 5 } & & Lokasi 1 & Lokasi 2 & Lokasi 3 & 13 \\
\hline 1 & $03: 01-06: 00$ & 74.8 & 77.5 & 82.7 & 69 \\
2 & $06: 01-09: 00$ & 98 & 84.1 & 91 & 33 \\
3 & $09: 01-11: 00$ & 86.6 & 83.1 & 84.4 & 69 \\
4 & $11: 01-14: 00$ & 83.2 & 85.6 & 88.6 & 71 \\
5 & $14: 01-17: 00$ & 84.2 & 88.3 & 89.2 & 74 \\
6 & $17: 01-20: 00$ & 82.3 & 92.6 & 87.6 & 26 \\
7 & $20: 01-22: 00$ & 89.6 & 92.1 & 100.3 & 1 \\
8 & $22: 01-03: 00$ & 77 & 85.7 & 80.5 & 356 \\
\hline \hline
\end{tabular}

Tabel 2.

Fluktuasi Tingkat Kebisingan Hari Ke 2

\begin{tabular}{rrrrrr}
\hline \hline \multirow{2}{*}{ No } & Periode & \multicolumn{3}{c}{ Tingkat Kebisingan (dB) } & \multirow{2}{*}{$\begin{array}{c}\text { Jumlah } \\
\text { Pesawat }\end{array}$} \\
\cline { 3 - 5 } & & Lokasi 1 & Lokasi 2 & $\begin{array}{c}\text { Lokasi } \\
\text { Pes }\end{array}$ & \\
\hline 1 & $03: 01-06: 00$ & 79 & 76.1 & 81.8 & 13 \\
2 & $06: 01-09: 00$ & 89.7 & 89.7 & 86.9 & 78 \\
3 & $09: 01-11: 00$ & 80 & 85.7 & 93.7 & 48 \\
4 & $11: 01-14: 00$ & 84 & 98 & 92.2 & 69 \\
5 & $14: 01-17: 00$ & 80 & 88.2 & 93.5 & 59 \\
6 & $17: 01-20: 00$ & 85.7 & 97.5 & 98.6 & 57 \\
7 & $20: 01-22: 00$ & 96.5 & 85.5 & 83.9 & 54
\end{tabular}

\begin{tabular}{rrrrrr}
8 & $22: 01-03: 00$ & 75 & 92 & 88.9 & 5 \\
Ldn & & 72.18 & 76.18 & 75.97 & 383 \\
\hline \hline
\end{tabular}

Tabel 3.

Fluktuasi Tingkat Kebisingan Hari Ke 3

\begin{tabular}{rrrrrr}
\hline \hline \multirow{2}{*}{ No } & Periode & \multicolumn{3}{c}{ Tingkat Kebisingan $(\mathrm{dB})$} & \multirow{2}{*}{ Jumlah } \\
\cline { 3 - 4 } & & Lokasi 1 & Lokasi 2 & Lokasi 3 & Pesawat \\
\hline 1 & $03: 01-06: 00$ & 83.4 & 81.3 & 87.6 & 15 \\
2 & $06: 01-09: 00$ & 88.6 & 92.9 & 95.5 & 76 \\
3 & $09: 01-11: 00$ & 88.5 & 87.3 & 93.7 & 51 \\
4 & $11: 01-14: 00$ & 82 & 90.5 & 91.3 & 61 \\
5 & $14: 01-17: 00$ & 83.3 & 92.5 & 93.4 & 79 \\
6 & $17: 01-20: 00$ & 92 & 94.6 & 96.7 & 78 \\
7 & $20: 01-22: 00$ & 94.2 & 92.6 & 94.4 & 48 \\
8 & $22: 01-03: 00$ & 78.7 & 92.6 & 80.3 & 19 \\
Ldn & & 71.70 & 74.50 & 76.14 & 427 \\
\hline \hline
\end{tabular}

Pada penelitian ini, kebisingan yang terjadi direpresentasikan dalam $L d n$. Persamaan (1) kemudian dituliskan dalam $L d n$ sebagai berikut:

$$
L d n=10 \log \left[(D+E+c N) 10^{E L / 10}\right]-49,4
$$

Jumlah pesawat pada siang, sore, dan malam atau disimbolkan dengan $D, E, N$ akan disubstitusi dengan simbol yang merepresentasikan jumlah pesawat tiba dan berangkat sehingga membentuk model matematika. Dengan melalukan substitusi

$D+E=x_{j S 10}+x_{j S 28}+y_{j S 10}+y_{j S 28} \quad$ dan $\quad N=x_{j M 10}+$ $x_{j M 28}+y_{j M 10}+y_{j M 28}$ diperoleh persamaan (4.1) dimana $j$ adalah jenis penerbangan, domestik dan internasional.

$$
\begin{gathered}
L d n=10 \log \left(\sum_{j=1}^{2}\left(x_{j S 10}+x_{j S 28}+10\left(x_{j M 10}+x_{j M 28}\right)\right) 10^{\frac{N E L}{10}}\right. \\
\left.+\left(y_{j S 10}+y_{j S 28}+10\left(y_{j M 10}+y_{j M 28}\right)\right) 10^{\frac{N E L}{10}}\right) \\
-49.4 .
\end{gathered}
$$

Tingkat kebisingan, $L d n$ mempunyai bobot kebisingan. Berdasarkan referensi 7 , bobot kebisingan yang terjadi dirumuskan dalam fungsi berikut [6].

$$
W(L d n)=\frac{\left[3.364 \times 10^{-6}\right]\left[10^{0.03 L d n}\right]}{[0.2]\left[10^{0.03 L d n}\right]+\left[1.43 \times 10^{-4]\left[10^{0.08 L d n}\right]} .\right.}
$$

Pada model Les Frair, kebisingan dipresentasikan dalam fungsi bobot kebisingan, $W(L d n)_{A}$. Nilai minimum kebisingan bergantung pada fungsi bobot kebisingan. Optimalisasi dilakukan dengan meminimukan fungsi bobot, yang kemudian dirumuskan menjadi tujuan. Fungsi objektif dirumuskan sebagai berikut :

$Z=\sum_{A=1}^{n} W(L d n)_{A} \frac{P_{A}}{P}$,

$P_{A}=$ luas daerah $\mathrm{A}$

$P=$ luas daerah total

Fungsi tujuan pada persamaan (5) mempunyai penyelesaian pada fungsi $W(L d n)_{A}$, dimana $W(L d n)_{A}$ bergantung pada 
$L d n$. Berikut ini disimbolkan $S_{A}$ untuk mempermudah penulisan solusi optimal pada bagian selanjutnya.

$$
\begin{gathered}
S_{A}= \\
\left(\sum_{j=1}^{2}\left(x_{j S 10}+x_{j S 28}+10\left(x_{j M 10}+x_{j M 28}\right)\right) 10^{\frac{N E L}{10}-4.94}+\right. \\
\left.\left(y_{j S 10}+y_{j S 28}+10\left(y_{j M 10}+y_{j M 28}\right)\right) 10^{\frac{N E L}{10}-4.94}\right) .
\end{gathered}
$$

Dari persamaan (3) dan (6) didapatkan :

$$
L d n=10 \log \left(S_{A}\right)
$$

Dengan substitusi persamaan (4) dan (5) diperoleh persamaan fungsi tujuan yang akan dioptimalkan.

$Z=\sum_{A=1}^{n} \frac{P_{A}}{P} \frac{3,364 \times 10^{-6} S_{A}{ }^{1,03}}{0,02 S_{A}{ }^{0.3}+1,43 \times 10^{-4} S_{A}{ }^{0.8}}$

Tingkat kebisingan yang diinginkan memiliki kaitan dengan kondisi lingkungan pada suatu bandara. Terdapat beberapa kondisi yang kemudian menjadi kondisi batasan. Adapun batas-batas penerbangan tersebut disusun berdasarkan :

1. Jumlah pesawat yang beroperasi dalam satu hari

2. Jumlah pesawat yang beroperasi selama periode siang dan malam

3. Jenis penerbangan yaitu penerbangan domestik dan penerbangan internasional

4. Runway atau jalur lintasan take off dan landing yang digunakan

Batasan-batasan diatas diperoleh dari data penerbangan pada Bandara Juanda. Secara matematis, batas-batas diatas dirumuskan dalam persamaan (8) hingga (17).

$$
\begin{gathered}
x_{D S 10}+x_{D S 28}+x_{D M 10}+x_{D M 28}+y_{D S 10}+y_{D S 28}+y_{D M 10} \\
+y_{D M 28} \leq 348
\end{gathered}
$$$$
x_{I n S 10}+x_{I n S 28}+x_{I n M 10}+x_{I n M 28}+y_{I n S 10}+y_{I n S 28}
$$$$
+y_{\text {InM } 10}+y_{\text {InM } 28} \leq 35
$$$$
x_{D S 10}+x_{D S 28}+x_{I n S 10}+x_{I n S 28}+y_{D S 10}+y_{D S 28}+y_{I n S 10}
$$$$
+y_{\text {InS28 }} \leq 341
$$$$
y_{I n S 10}+y_{I n S 28}+x_{I n M 10}+x_{I n M 28}
$$

$$
\begin{gathered}
+y_{D M 10}+y_{D M 28}+y_{I n M 10}+y_{I n M 28} \leq 42 \\
y_{I n M 10}+y_{\text {InM } 28}=0 \\
x_{\text {InM } 10}+x_{\text {InM } 28} \leq \\
y_{D M 10}+y_{D M 28} \leq 10 \\
y_{\text {InS10 }}+y_{\text {InS } 28} \leq 16
\end{gathered}
$$

Berdasarkan solusi optimum $\mathrm{S}$ dan persamaan (6) persamaan batas penerbangan dirumuskan

$$
\begin{aligned}
& 10 \log \left[\left(\sum_{i=1}^{2}\left(x_{j S 10}+x_{j S 28}+10\left(x_{j M 10}+x_{j M 28}\right)\right) 10^{\frac{N E L}{10}}+\right.\right. \\
& \left.\left.\left(y_{j S 10}+y_{j S 28}+10\left(y_{j M 10}+y_{j M 28}\right)\right) 10^{\frac{N E L}{10}}\right)-49.4\right] \leq L d n
\end{aligned}
$$

$$
\begin{aligned}
10 \log \left[\left(x_{D S 10}+\right.\right. & x_{D S 28}+x_{I n S 10}+x_{I n S 28} \\
& +10\left(x_{D M 10}+x_{D M 28}+x_{I n M 10}+x_{I n M 28}\right) \\
& +y_{D S 10}+y_{D S 28}+y_{I n S 10}+y_{I n S 28} \\
& +10\left(y_{D M 10}+y_{D M 28}+y_{I n M 10}\right. \\
& \left.\left.\left.+y_{I n M 28}\right)\right) 10^{\frac{N E L}{10}}\right] \leq L d n
\end{aligned}
$$

dengan :

$x \quad$ jumlah pesawat berangkat

$y \quad$ jumlah pesawat tiba

$D \quad$ penerbangan domestik

In penerbangan internasional

$S \quad$ periode siang

$M$ periode malam

10 runway 10

28 runway 28

Persamaan (7) didekati dengan deret Taylor di sekitar titik $S=1 \times 10^{6}$ untuk membentuk fungsi $F(S)$.

$F\left(S_{A}\right)=Z(S)+Z^{\prime}(S)\left(S_{A}-S\right)+Z^{\prime \prime}\left(S_{A}-S\right)^{2} / 2$

$F\left(S_{A}\right)=Z\left(10^{6}\right)+Z^{\prime}\left(10^{6}\right)\left(S_{A}-10^{6}\right)+Z^{\prime \prime}\left(S_{A}-10^{6}\right)^{2} / 2$

$F\left(S_{A}\right)=0.3508+(1.4424 e-007) x-(5.7769 e$

$$
-014)\left(x-10^{6}\right)^{2}
$$

Solusi dari persamaan $F\left(S_{A}\right)$ diperoleh dengan melakukan iterasi Newton Raphson dengan nilai awal $S_{a}$.

$$
S_{A_{k+1}}=S_{A_{k}}-\frac{F\left(S_{A_{k}}\right)}{F^{\prime\left(S_{A_{k}}\right)}} \text { dengan } k=1,2,3, \ldots
$$

dengan error $\varepsilon=5 \times 10^{-10}$. Nilai awal $S_{a}=547.894 .249$ adalah rata-rata nilai $S_{a}$ dari hasil pengukuran dilapangan. Data hasil pengukuran terlampir pada Lampiran 3. Perhitungan dilakukan dengan software MATLAB, program terlampir. Iterasi menghasilkan solusi optimal pada titik $S_{o}=5.430 .926,077 . U(S)$ adalah fungsi $\mathrm{Z}$ yang didekati pada $S_{o}$ untuk mengetahui apakah terdapat solusi yang lebih tepat.

$$
\begin{gathered}
U(S)=Z\left(S_{o}\right)+Z^{\prime}\left(S_{o}\right)\left(S-S_{o}\right)+Z^{\prime \prime}\left(S-S_{o}\right)^{2} / 2 \\
U(S)=(3.7367 e-008) x-(2.7294 e-015)(x \\
\left.-(5.4309 e+006))^{\wedge} 2\right)+0.5827 \\
U^{\prime}(S)=(6.7014 e-008)-(5.4589 e-015) x
\end{gathered}
$$

Solusi awal dari persamaan tersebut didapatkan saat $U^{\prime}(S)=$ 0 . Solusi optimal dari persamaan (18) adalah $S_{1}$. Iterasi dilakukan untuk mendapatkan nilai solusi optimal saat dipenuhi syarat $U\left(S_{1}\right)<U\left(S_{o}\right)$. Jika $U\left(S_{1}\right)<U\left(S_{o}\right)$, terdapat $S_{2}$ diantara $S_{1}$ dan $S_{o}$ dimana $\mathrm{Z}\left(S_{2}\right)<Z\left(S_{o}\right)$. Nilai $S_{2}$ adalah variabel bebas dalam $S$ sehingga untuk $0 \leq \alpha \leq 1, Z$ minimum pada

$$
Z\left(S_{2}\right)=Z\left(S_{o}+\alpha\left(S_{1}-S_{o}\right)\right)
$$

Nilai $S_{o}$ berubah menjadi nilai $S_{2}$. Iterasi dilakukan sampai memenuhi kondisi $U\left(S_{1}\right) \geq U\left(S_{o}\right)$. Perhitungan diatas dilakukan dengan simulasi pada software MATLAB menghasilkan solusi optimal $S_{1}=12.276 .185,62$. Code MATLAB terlampir di lampiran. Nilai $S_{1}=12.276 .185,62$ menghasilkan nilai $L d n=70,89063447$, dengan menggunakan persamaan (7). Nilai $L d n$ optimal akan disubstitusi ke persamaan (17) menjadi 


$$
\begin{aligned}
x_{D S 10}+x_{D S 28}+ & x_{I n S 10}+x_{I n S 28} \\
& +10\left(x_{D M 10}+x_{D M 28}+x_{I n M 10}+x_{I n M 28}\right) \\
& +y_{D S 10}+y_{D S 28}+y_{I n S 10}+y_{I n S 28} \\
& +10\left(y_{D M 10}+y_{D M 28}+y_{I n M 10}+y_{I n M 28}\right) \\
& \leq 756
\end{aligned}
$$

Perbandingan bobot kebisingan optimal dan sebelum dioptimalkan dapat diketahui dengan melihat indeks dampak kebisingan. Indeks dampak kebisingan atau Noise Impact Index dihitung dengan menggunakan rumus :

$$
\begin{aligned}
& N I I=\frac{L W P}{P \operatorname{total}} \\
& L W P=\frac{W(L d n)+W(L d n+5)}{2}
\end{aligned}
$$

Tabel 4.

Perbandingan Nilai Noise Impact Index

\begin{tabular}{ccccc}
\hline \hline Hari & Lokasi & NII Awal & NII Optimal & $\%$ \\
\hline & 1 & 1.108032903 & 0.893602889 & 21.44300138 \\
1 & 2 & 0.957991108 & 0.893602889 & 6.43882193 \\
& 3 & 1.315622758 & 0.893602889 & 42.20198684 \\
& 1 & 0.987704497 & 0.893602889 & 9.41016080 \\
2 & 2 & 1.317759799 & 0.893602889 & 42.41569096 \\
& 3 & 1.299335228 & 0.893602889 & 40.57323390 \\
& 1 & 0.951596346 & 0.893602889 & 5.79934570 \\
3 & 2 & 1.171879346 & 0.893602889 & 27.82764570 \\
& 3 & 1.314190735 & 0.893602889 & 42.05878454 \\
\hline \hline
\end{tabular}

Runway usage bergantung pada dua hal, yaitu penggunaan berdasarkan faktor arah angin dan berdasarkan dampak pada daerah yang dilalui. Penggunaan berdasarkan faktor arah angin memprioritaskan keselamatan penerbangan, sedangkan penggunaan berdasarkan dampak pada daerah yang dilalui memprioritaskan dampak pada lingkungan termasuk kebisingan. Apabila mengacu pada arah angin maka sewaktuwaktu solusi yang diberikan pada Tabel 5. dapat diubah pada penggunaan runway 10 dan runway 28. Apabila mengacu pada dampak yang ditimbulkan pada lingkungan, terutama lingkungan padat penduduk, sekolah dan gedung yang tinggi

\begin{tabular}{|c|c|c|c|c|c|c|c|c|}
\hline \multirow{2}{*}{$\begin{array}{c}\text { Jumla } \\
\text { h }\end{array}$} & \multirow{2}{*}{$\begin{array}{l}\text { Beran } \\
\text { g-kat }\end{array}$} & \multirow{2}{*}{ Tiba } & \multicolumn{2}{|c|}{$\begin{array}{c}\text { Tipe } \\
\text { Penerbanga } \\
\mathrm{n} \\
\end{array}$} & \multicolumn{2}{|c|}{$\begin{array}{c}\text { Periode } \\
\text { Penerbangan }\end{array}$} & \multicolumn{2}{|c|}{ Runway } \\
\hline & & & Dom & Intl & $\begin{array}{c}\text { Sian } \\
\mathrm{g}\end{array}$ & $\begin{array}{c}\text { Mala } \\
\mathrm{m}\end{array}$ & 10 & 28 \\
\hline 3 & $\mathrm{x}$ & & & $\mathrm{x}$ & & $\mathrm{x}$ & $\mathrm{x}$ & \\
\hline 19 & $\mathrm{x}$ & & $\mathrm{x}$ & & & $\mathrm{x}$ & $\mathrm{x}$ & \\
\hline 16 & $\mathrm{x}$ & & & $\mathrm{x}$ & $\mathrm{x}$ & & $\mathrm{x}$ & \\
\hline
\end{tabular}
maka solusi jadwal penerbangan pada Tabel 5 dapat

\begin{tabular}{|c|c|c|c|c|c|c|c|c|}
\hline 150 & $\mathrm{X}$ & & $\mathrm{X}$ & & $\mathrm{x}$ & & $\mathrm{X}$ & \\
\hline 36 & $x$ & & $x$ & & $x$ & & & $\mathrm{x}$ \\
\hline 0 & & $\mathrm{x}$ & & $\mathrm{x}$ & & $\mathrm{x}$ & & $\mathrm{X}$ \\
\hline 10 & & $\mathrm{x}$ & $\mathrm{X}$ & & & $\mathrm{x}$ & $\mathrm{X}$ & \\
\hline 16 & & $\mathrm{x}$ & & $\mathrm{x}$ & $\mathrm{x}$ & & $\mathrm{x}$ & \\
\hline 158 & & $x$ & $\mathrm{x}$ & & $\mathrm{x}$ & & $\mathrm{x}$ & \\
\hline 60 & & $\mathrm{x}$ & $\mathrm{x}$ & & $\mathrm{x}$ & & & $\mathrm{x}$ \\
\hline 50 & & $\mathrm{x}$ & $\mathrm{x}$ & & $\mathrm{x}$ & & & $\mathrm{x}$ \\
\hline
\end{tabular}
digunakan. Tabel 5. adalah salah satu alternatif jadwal penerbangan yang dapat digunakan dalam pengelolaan jadwal penerbangan.

Tabel 5.

Jadwal Keberangkatan dan Kedatangan dengan NII $=0.893602889$

\section{KESIMPULAN DAN SARAN}

Berdasarkan analisa dan pembahasan diatas, dapat diambil beberapa kesimpulan sebagai berikut :

1. Hasil pemodelan $L d n$ dan $\mathrm{Z}$ yang diperoleh adalah

$$
\begin{aligned}
L d n=10 \log \left[\sum _ { i = 1 } ^ { 2 } \left(x_{i S 10}+x_{i S 28}\right.\right. \\
\left.\quad+10\left(x_{i M 10}+x_{i M 28}\right)\right) 10^{\frac{N E L}{10}}+\left(y_{i S 10}\right. \\
\left.\left.\quad+y_{i S 28}+10\left(y_{i M 10}+y_{i M 28}\right)\right) 10^{\frac{N E L}{10}}\right] \\
\quad-49.4 \\
Z=\sum_{A=1}^{n} \frac{P_{A}}{P} \frac{3,364 \times 10^{-6} S_{A}{ }^{1,03}}{0,02 S_{A}{ }^{0.3}+1,43 \times 10^{-4} S_{A}{ }^{0.8}}
\end{aligned}
$$

Dimana hubungan $L d n$ dan $S_{A}$ adalah $L d n=10 \log S_{A}$, sehingga jumlah pesawat, $L d n$ dan $\mathrm{Z}$ saling mempengaruhi.

2. Indeks dampak kebisingan mengalami penurunan dari $5.79934570 \%$ hingga $42.41569096 \%$ setelah dioptimalkan. Hal ini berarti dampak kebisingan yang terjadi berkurang hingga $42.41569096 \%$ tepatnya berada di lokasi 2 pada hari ke 2.

3. Terdapat variasi penurunan indeks kebisingan atau NII. Hal ini diakibatkan oleh tingkat $L d n$ yang berbeda di setiap titik pengukuran, dimana pada jarak $6,5 \mathrm{~km}$ tingkat kebisingan sudah optimal untuk daerah perdagangan, rekreasi dan industri

4. Penjadwalan penerbangan yang diuraikan merupakan salah satu alternatif karena penggunaan runway sangat dipengaruhi oleh arah angin.

Penelitian ini dapat berkembang sesuai dengan perkembangan ilmu pengetahuan. Adapun saran yang diberikan oleh penulis untuk penelitian berikutnya adalah optimalisasi dan penjadwalan penerbangan dapat dilakukan dengan Noise Abatement. Optimalisasi kebisingan dengan Noise Abatement telah digunakan dibeberapa negara maju untuk mengatur lalu lintas penerbangan dengan memperhatikan kondisi geografis daerah-daerah yang dilalui oleh pesawat.

\section{UCAPAN TERIMAKASIH}

Penulis mengucapkan terimakasih kepada Bapak Halim dan Ibu Rosa yang telah membantu pendanaan survey dan alat, dan kepada semua pihak yang terlibat dalam penelitian ini.

\section{DAFTAR PUSTAKA}

[1] Direktorat Jenderal Perhubungan Udara, "Direktorat Jenderal 

Perhubungan Udara." $\quad$ [Online].
http://hubud.dephub.go.id/?id/bandara/index/page:30.

[2] Anonymous, "No Title." [Online]. Available: http://juandaairport.com/statistik-llau.

[3] M. Chaeran, "Kajian Kebisingan Akibat Aktifitas di Bandara (Studi Kasus Bandara Ahmad Yani Semarang)," Universitas Diponegoro, 2008.

[4] Kementrian Perhubungan, "Peraturan Menteri Perhubungan Nomor KM 4 tahun 2004 tentang 'Batas-batas Kawasan Kebisingan di Sekitar Bandar Juanda Surabaya,", 2004.

[5] D. P. Sangsoko, Kebisingan Lingkungan Semarang. Semarang: Badan Penerbit Universitas Diponegoro, 2000.

[6] L. Frair, "Airport Noise Modelling and Aircraft Schedulling so as to
Minimize Community Annoyance," Virginia, 1983.

[7] Menteri Lingkungan Hidup, "Keputusan Menteri Lingkungan Hidup No. 48 tahun 1996," 1996.

[8] Menteri Kesehatan, "Keputusan Menteri Kesehatan Republik Indonesia No 1405/Menkes/SK/XI/2012 tahun 2012 tentang Persyaratan Lingkungan Kerja Perkantorn dan Industri," 2012.

[9] N. M. Inc, "Noise Meter." [Online]. Available: https://www.noisemeters.com/help/faq/frequency-weighting.asp.

[10]B. P. Fahmi, "Pemetaan Kebisingan Akibat Aktifitas Pesawat dengan Software Integrated Noise Model (INM) di Sekitar Bandar Udara Internasional Soekarno-Hatta., Universitas Indonesia,” Depok, 2012. 